\title{
Two-year comparison of radiances from the Atmospheric Infrared Sounder (AIRS) and the Infrared Atmospheric Sounding Interferometer $(\mid \mathrm{ASI})$
}

Denis A. Elliott, Hartmut H. Aumann, L. Larrabee Strow, Scott E. Hannon

Denis A. Elliott, Hartmut H. Aumann, L. Larrabee Strow, Scott E. Hannon, "Two-year comparison of radiances from the Atmospheric Infrared Sounder (AIRS) and the Infrared Atmospheric Sounding Interferometer (IASI)," Proc. SPIE 7456, Atmospheric and Environmental Remote Sensing Data Processing and Utilization V: Readiness for GEOSS III, 74560S (12 August 2009); doi: 10.1117/12.826996

SPIE Event: SPIE Optical Engineering + Applications, 2009, San Diego, California, United States 


\title{
Two-year comparison of radiances from the Atmospheric Infrared Sounder (AIRS) and the Infrared Atmospheric Sounding Interferometer (IASI)
}

\author{
Denis A. Elliott ${ }^{\mathrm{a}}$, Hartmut H. Aumann ${ }^{\mathrm{a}}$, L. Larrabee Strow ${ }^{\mathrm{b}}$, and Scott E. Hannon ${ }^{\mathrm{b}}$ \\ ${ }^{a}$ Jet Propulsion Laboratory, California Institute of Technology, 4800 Oak Grove Drive, Pasadena, \\ CA, USA 91109; \\ ${ }^{b}$ University of Maryland, Baltimore County, 1000 Hilltop Circle, Baltimore, MD USA 21250
}

\begin{abstract}
The radiometric intercomparison of instruments is a key element in developing climate-quality data records. In this study we compare data from the first two years of the Infrared Atmospheric Sounding Interferometer (IASI) with the matching data from the Atmospheric Infrared Sounder (AIRS). We compare observed spectra in cloud-free areas of the tropical oceans at night to spectra calculated using data from the European Centre for Medium-Range Weather Forecasts (ECMWF). We use five frequencies - three window channels, one mid-tropospheric sounding channel, and one lower stratospheric sounding channel. The use of ECMWF data as a transfer standard permits comparisons of many more points distributed more widely over the globe than is possible with the traditional simultaneous nadir overpass (SNO) technique. The analysis shows that AIRS and IASI daily mean brightness temperatures track each other within $100 \mathrm{mK}$, in spite of the fact that the instruments are in different orbits. AIRS was launched into polar orbit on the EOS Aqua spacecraft on May 4, 2002. It is a grating spectrometer with 2378 channels in the range 3.7 to 15.4 microns. IASI was launched into polar orbit in October 2006 on the METOP-A spacecraft. IASI is a Fourier transform spectrometer covering 3.7 to 15.5 microns in three bands with a total of 8461 channels.
\end{abstract}

Keywords: Hyperspectral, infrared, polar orbiter, EOS Aqua, Metop-A, calibration

\section{INTRODUCTION}

Data from hyperspectral sounders have the potential of providing great insight into the response of the Earth's climate system to natural and anthropogenic causes. Changes in these quantities are on a multi-decadal scale with a nominal trend of $100 \mathrm{mK} / \mathrm{decade}^{1}$, but with considerably larger inter-annual variability. The ability reliably to detect differences from the $100 \mathrm{mK} /$ decade anticipated changes requires absolute calibration at the $30 \mathrm{mK}$ level. Changes on this amplitude scale can be measured reliably during the lifetime of a single instrument, but the nominal lifespan of any one instrument may only be five years. The creation of a climate quality record to measure changes on a longer time scale requires the combination of data from a sequence of hyperspectral instruments. Even if an instrument could be designed to achieve NIST traceable absolute accuracy at the $30 \mathrm{mK}$ level, and even if this accuracy was demonstrated during pre-launch testing, the harsh environment in orbit requires that this accuracy be validated throughout the life of an instrument. The day/night orbital and seasonal solar-beta-angle-related changes in the thermal environment are the largest contributors to various radiometric and spectral calibration artifacts, which affect both a grating array (AIRS) and a Fourier transform spectrometer (IASI) design, although in different ways. Validation of the absolute radiometric accuracy is made somewhat easier if there is a one-year or more overlap between instruments of established accuracy and stability in a sequence of missions. In this study we evaluate the potential and limitations of relative instrument calibration using data from the Atmospheric Infrared Sounder ${ }^{2}$ and the Infrared Atmospheric Sounder Interferometer ${ }^{3}$. AIRS was launched in May 2002 on the EOS Aqua spacecraft into a $705 \mathrm{~km}$ altitude sun-synchronous polar orbit with a 1:30 PM ascending node. IASI was launched in October 2006 on Metop-A into an $825 \mathrm{~km}$ altitude sun-synchronous polar orbit with a 9:30 AM ascending node.

Atmospheric and Environmental Remote Sensing Data Processing and Utilization V: Readiness for GEOSS III, edited by Mitchell D. Goldberg, Hal J. Bloom, Proc. of SPIE Vol. 7456, 74560S · @ 2009 SPIE

CCC code: $0277-786 \mathrm{X} / 09 / \$ 18 \cdot$ doi: $10.1117 / 12.826996$ 


\section{APPROACH}

Although AIRS and IASI are in different polar orbits, the data from the two instruments can be used for a radiance comparison, and the results of this comparison can be used to infer the absolute radiometric calibration accuracy. The most direct technique makes use of the fact that the orbits of the two instruments cross every day, producing one or two Simultaneous Nadir Overpass (SNO) measurements each day of the same scene at the same time and with the same (nadir) view. The technique we use produces thousands of measurements per day by relying on a transfer standard with stable error characteristics. For this we use data from the European Centre for Medium-Range Weather Forecasts (ECMWF). ECMWF generates surface temperature and atmospheric temperature and moisture profiles at 000Z, 600Z, $1200 \mathrm{Z}$ and $1800 \mathrm{Z}$, interlaced by a 3 -hour forecast at $0300 \mathrm{Z}, 0900 \mathrm{Z}, 1500 \mathrm{Z}$ and $2100 \mathrm{Z}$. Their analysis is based on the assimilation of surface truth and satellite data. We use the ECMWF data under cloud-free conditions to calculate the infrared brightness temperatures which we expect each instrument to measure and compare them with the observed values. We define the quantity "obs" to be the actually observed radiances for the channels of interest. The quantity "calc" is the integral over each channel's spectral response function (SRF) of the expected upwelling radiance calculated from the ECMWF $\mathrm{T}(\mathrm{p}), \mathrm{q}(\mathrm{p})$, and TSurf specification of the state of the atmosphere. The conversion of ECMWF temperature profiles to a top-of-the-atmosphere brightness temperature uses the radiative transfer code developed for AIRS and IASI by Strow ${ }^{4}$ including the surface emissivity from Masuda ${ }^{5}$ and surface skin effect $(0.17 \mathrm{~K}$ based on Donlon ${ }^{6}$ ). The ECMWF surface temperatures from before September 2008 were explicitly corrected for the diurnal variability based on Kennedy ${ }^{7}$. This results in a $0.2 \mathrm{~K}$ correction for the 1:30 AM overpass and 0.05K for the 9:30 PM overpass. Starting in September 2008 the diurnal effect is included in the ECMWF surface temperature. The use of ECMWF for "calc" makes any evaluation of seasonal patterns or trends sensitive to the accuracy and/or version changes in the ECMWF model. We assume that whatever biases may be in the ECMWF data, there is no systematic difference or trend between the 9:30 PM IASI and 1:30 AM AIRS overpass times. With this assumption biases common to the AIRS and IASI (obs-calc) cancel to first order in the double-difference.

Accurate knowledge of the SRF shape and positions is critical to the accuracy of "calc". The SRF shape for AIRS is frozen into the design as the convolution of the spectrometer entrance slit with the exit slit. The pre-launch measured values were used $\left[\mathrm{Strow}^{4}\right]$. The SRF centroid positions for all 2378 AIRS spectral channels are determined by a single parameter $\mathrm{y}_{0}$, the effective focal plane offset, and the prelaunch determined positions of the detector arrays, which are also frozen into the design $\left[\mathrm{Strow}^{4}\right]$. The $\mathrm{y}_{0}$ parameter has a small time dependence [Manning ${ }^{8}$ ], which is measured routinely within 1 part per million (ppm) in frequency using resolved features due to $\mathrm{CO}_{2}$ in the upwelling spectra, but is not corrected in the AIRS Level 1B radiances. For the "calc" used in the present paper we used a fixed $\mathrm{y}_{0}=-14.0 \mu \mathrm{m}$, the mean value appropriate to the 2007/2008 time period. For "obs" we used the operational Level 1B product, i.e. the raw calibrated radiances, which are not corrected for the known $\mathrm{y}_{0}$ offset. This effectively introduces a 5 ppm uncertainty in the SRF centroid frequencies.

For IASI the SRF centroids are given in principle by the frequency of the metrology laser, its alignment relative to the interferometer optical axis, and the positions of the detectors relative to the interferometer optical axis (the obliquity correction), all determined in the pre-launch calibration. In practice this alignment changes with time, but is measured routinely in orbit using resolved features due to $\mathrm{CO}_{2}$ in the upwelling spectra with an accuracy that meets the $2 \mathrm{ppm}$ requirement [Péquignot ${ }^{9}$. The ground-based spectral calibration software applies the appropriate obliquity correction to the raw radiances, applies a strong apodization to the $2 \mathrm{~cm}$ Optical Path Difference (OPD) interferograms and creates a Level 1C product sampled on a uniform $0.25 \mathrm{~cm}^{-1}$ spectral frequency grid with a nominal $2 \mathrm{ppm}$ accuracy and $0.5 \mathrm{~cm}^{-1}$ SRF width. The IASI radiative transfer used for "calc" assumed a $2 \mathrm{~cm}$ OPD Gaussian apodization to emulate the 0.5 $\mathrm{cm}^{-1} \mathrm{SRF}$ width. For "obs" we used the operational IASI Level 1C product, which is frequency corrected.

The AIRS and IASI data were selected with slightly different cloud screening filters. Both rely on spatial coherence, that is that differences in the radiances from surface channels from adjacent footprints are indicative of the presence of clouds. For AIRS we use the spatial coherence of the $3 \times 3$ footprints for AIRS measured in the $1231 \mathrm{~cm}^{-1} \mathrm{channel}$. The IASI spectra were cloud filtered using the spatial coherence of the $2 \times 2$ footprints in the $1231 \mathrm{~cm}^{-1}$ IASI channel and the spatial homogeneity based on the standard deviation of the IASI 11 um imager pixels, which cover the IASI FOV. Although only about $0.5 \%$ of the spectra in the night tropical oceans pass the cloud-screening tests, this corresponds to typically 4000 spectra per day from AIRS and IASI. We used data from May 2007 through February 2009, although technically the IASI data were not considered to be in operational mode until July 2007. 
This methodology produces "cloud-free" (obs-calc) datasets for both IASI and AIRS for each day. The spatial and temporal coverage differs for the two instruments, so the cloud-free locations can change in the four hours separating the observations. We assume that, whatever biases may exist in the ECMWF results, there is no systematic difference between 9:30 PM and 1:30 AM analyses. In that case, the calculation bias cancels in the comparison of (obs-calc) for IASI versus (obs-calc) for AIRS. Since the same radiative transfer theory is used for both datasets, uncertainties in the spectroscopy cancel to first order as well.

Various approaches can be taken for the analysis of the daily data sets of cloud-free AIRS (obs-calc) and IASI (obscalc). Since AIRS and IASI data are available on different frequency grids, we use the simplest approach of analyzing the mean (obs-calc). This eliminates the need to shift the AIRS and IASI data to a common frequency grid. Very interesting insights into system performance can also be obtained from the analysis of the standard deviation of (obscalc), but this is outside of the scope of this paper.

\section{RESULTS}

Rather than showing the two-year mean of (obs-calc) as function of frequency, we focus on the daily means from selected channels as function of time for three surface channels at 2616,1231 and $961 \mathrm{~cm}^{-1}$, one mid-tropospheric channel at $712.75 \mathrm{~cm}^{-1}$, and one lower stratospheric channel at $700.25 \mathrm{~cm}^{-1}$.

\section{1 (obs - calc) for three window channels}

Radiometric accuracy and spectral calibration accuracy are interrelated in a hyperspectral sounder, since in the presence of a spectral gradient small uncertainties in the assumed position of the SRF can result in significant radiometric uncertainties. For window channels this is less of an issue, if they are selected in broad areas where the atmosphere is highly transparent.

\section{$2616 \mathrm{~cm}^{-1}$}

The $2616 \mathrm{~cm}^{-1}$ region is covered in AIRS detector module M2b and in IASI Band 3. The channels in the $2600-2650 \mathrm{~cm}^{-1}$ range include some of the most transparent windows in the infrared. The correction for atmospheric water vapor is therefore the least sensitive to uncertainties in the water vapor in the atmospheric column. The most transparent channel is at $2616.3 \mathrm{~cm}^{-1}$. The IASI data in this part of the spectrum are very noisy on a per channel basis. Of the 200 IASI channels between 2600 and $2650 \mathrm{~cm}^{-1}, 81$ are relatively good window channels. We averaged those to create an AIRSequivalent $2616.3 \mathrm{~cm}^{-1}$ channel. The resulting (obs-calc) is shown in Figure 1. Each plotted point is the mean for one

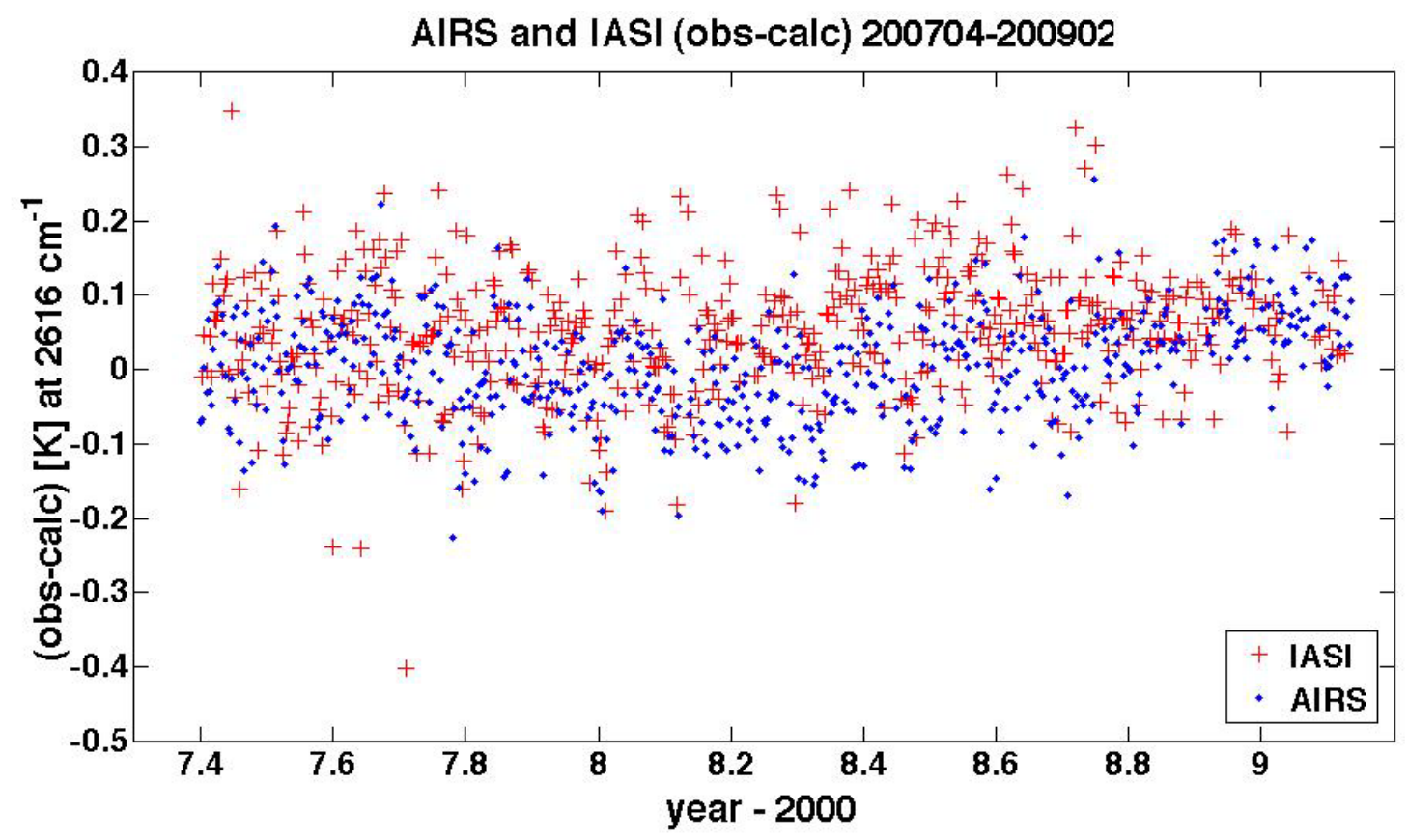

Figure 1. Daily mean (obs-calc) at $2616 \mathrm{~cm}^{-1}$ for AIRS and IASI 
day, based on typically 4000 clear spectra. The decrease in the scatter starting in September 2008 is due to an improved ECMWF surface model.

The mean sea surface temperature (SST) for the $2616 \mathrm{~cm}^{-1}$ data was $299 \mathrm{~K}$, but the average observed brightness temperature was $298 \mathrm{~K}$, due to typically $0.5 \mathrm{~K}$ of atmospheric absorption, and an emissivity correction of typically $0.5 \mathrm{~K}$. The bias of (obs-calc) for AIRS is $0.007 \mathrm{~K}$; for IASI it is $+0.053 \mathrm{~K}$.

\section{$1231 \mathrm{~cm}^{-1}$}

The $1231 \mathrm{~cm}^{-1}$ region is covered in array M4d on AIRS and in IASI Band 2. The IASI channel at $1231.25 \mathrm{~cm}^{-1}$ and the AIRS channel at $1231.3 \mathrm{~cm}^{-1}$ are both very low noise, so they were used directly. The mean brightness temperature for these data was $296 \mathrm{~K}$ due to a typically $3 \mathrm{~K}$ water vapor and a $1 \mathrm{~K}$ emissivity correction. The mean (obs-calc) is -0.131 $\mathrm{K}$ for AIRS and for IASI it is $-0.167 \mathrm{~K}$. Figure 2 shows the daily mean (obs-calc) for the $1231.25 \mathrm{~cm}^{-1}$ window channel from AIRS and IASI.

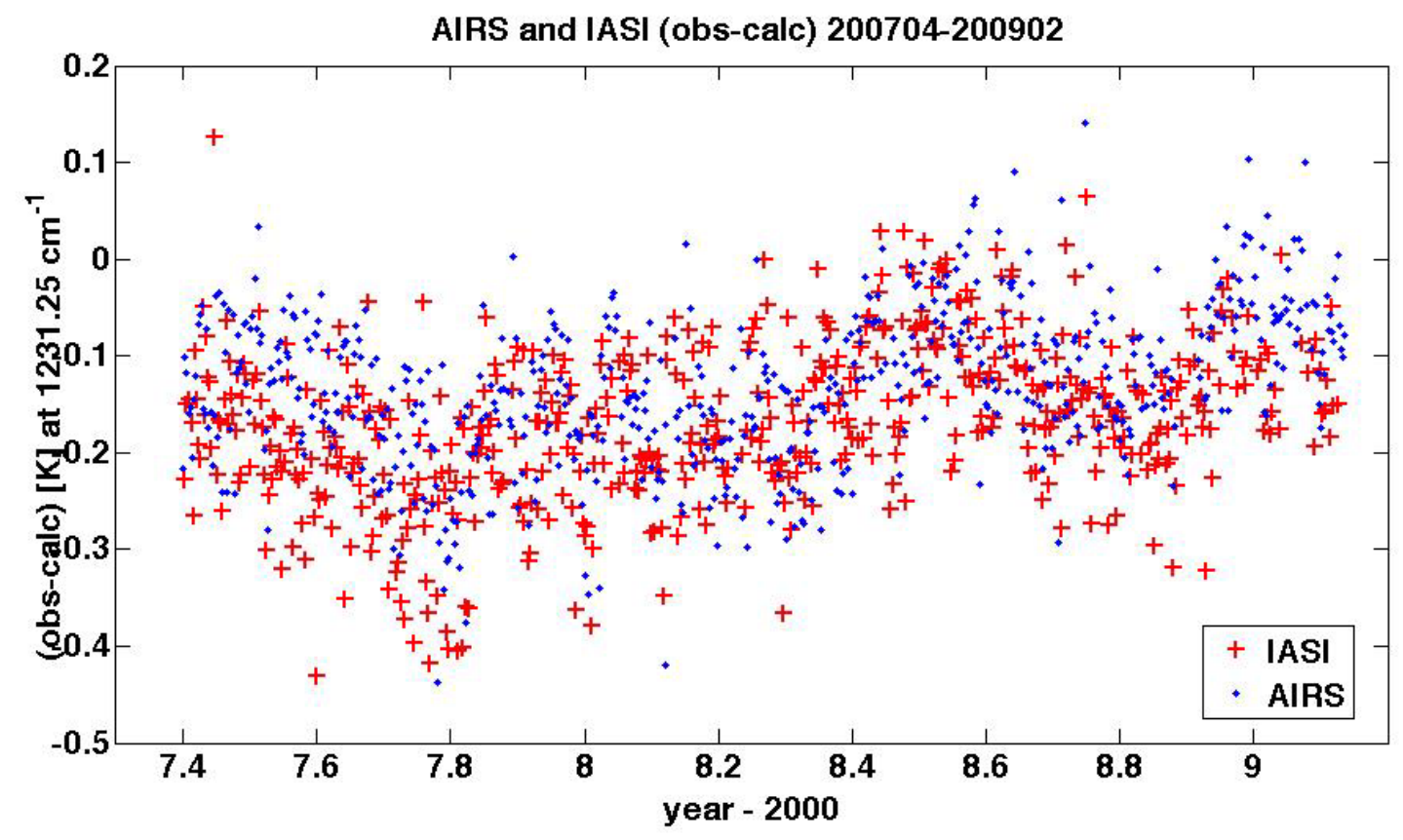

Figure 2. The daily mean (obs-calc) for the $1231.25 \mathrm{~cm}^{-1}$ window channel

\section{$961.5 \mathrm{~cm}^{-1}$}

The $961 \mathrm{~cm}^{-1}$ region is covered in array M7 in AIRS and in IASI Band 1. The atmospheric correction at the $961 \mathrm{~cm}^{-1}$ window channel is very close to that of the $1231 \mathrm{~cm}^{-1}$ region ( $3 \mathrm{~K}$ water vapor and a $1 \mathrm{~K}$ emissivity correction). Figure 3 shows the daily mean (obs-calc) from AIRS and IASI.

The two-year mean of (obs-calc) at $961 \mathrm{~cm}^{-1}$ for AIRS is $+0.089 \mathrm{~K}$; for IASI it is $-0.013 \mathrm{~K}$. The mean brightness temperature is $296 \mathrm{~K}$.

\section{2 (obs - calc) for temperature sounding channels}

For window channels the precise knowledge of the SRF shape and centroid position is not critical for data with hyperspectral resolution, since window channels can be selected from broad spectral areas (relative to the SRF width) where the atmosphere is highly transparent. But this is not the case for sounding channels.

The fact that radiometric accuracy and spectral calibration accuracy are interrelated becomes obvious in the inspection of a typical (tropical) spectrum for such channels. This is illustrated in Figure 4 for the 710 to $718 \mathrm{~cm}^{-1}$ tropospheric temperature sounding region. The IASI data are sampled on a uniform $0.25 \mathrm{~cm}^{-1}$ grid. The black curve interpolates 
through the IASI samples with $0.05 \mathrm{~cm}^{-1}$ steps. The spectral gradients in this region range from $-40 \mathrm{~K} / \mathrm{cm}^{-1}$ to +40 $\mathrm{K} / \mathrm{cm} \bullet^{1}$. An uncertainty of 2 parts per million in the knowledge of the frequency of the SRF centroid is equivalent to a $0.0014 \mathrm{~cm}^{-1}$ spectral shift, which can result in a radiometric error of up to $40 * 0.0014=0.058 \mathrm{~K}$.

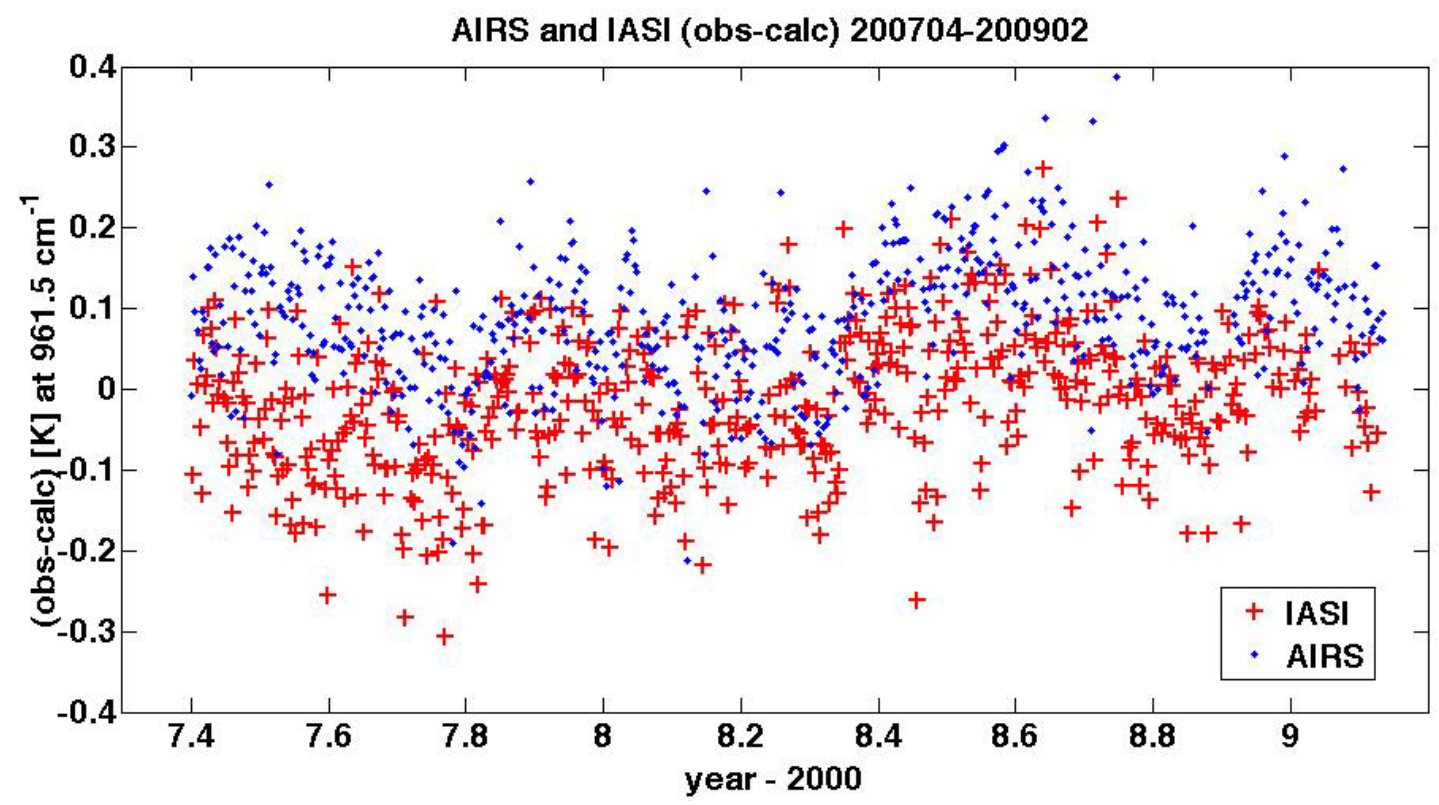

Figure 3. The daily mean (obs-calc) from AIRS and IASI for the $961 \mathrm{~cm}^{-1}$ channel

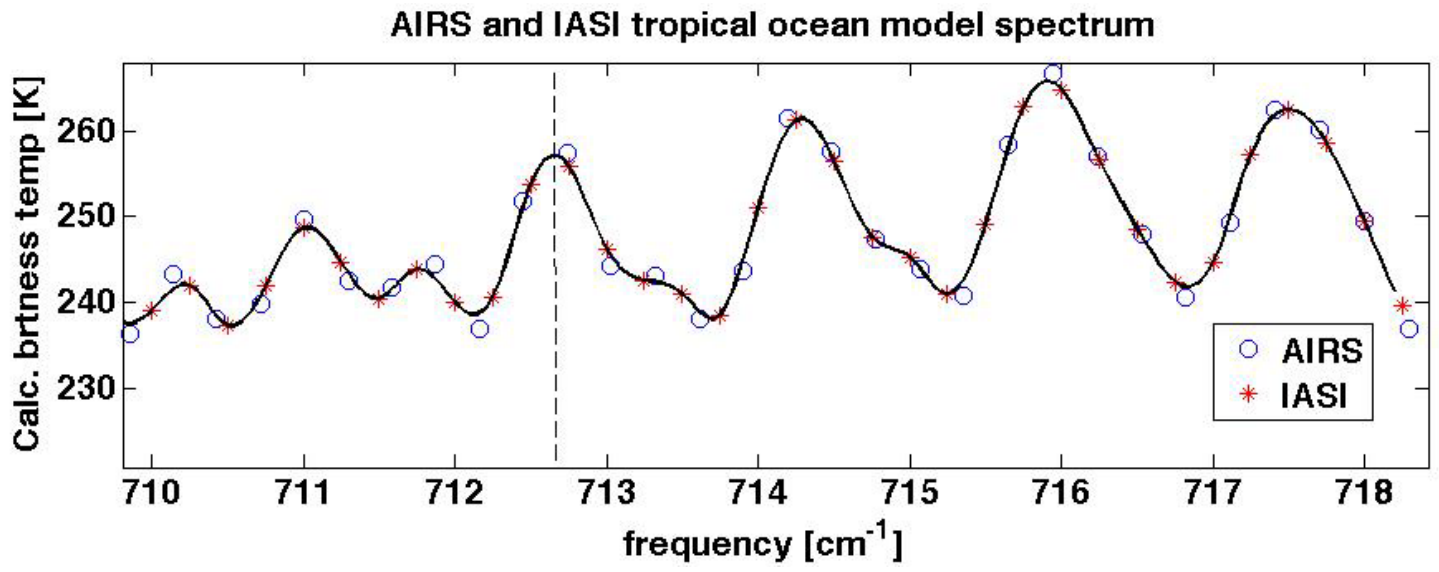

Figure 4. The calculated tropical spectrum from AIRS and IASI for the 710 to $718 \mathrm{~cm}^{-1}$ region

$712.75 \mathrm{~cm}^{-1}$

This channel sounds the atmosphere near $370 \mathrm{hPa}$, where the temperature is typically $256 \mathrm{~K}$. Since the SNR and spectral resolution in this region for AIRS and IASI are similar, channel averaging was not required. We selected the channel near a local minimum of opacity, but the spectral gradient at this location is still $25 \mathrm{~K} / \mathrm{cm}^{-1}$. The (obs-calc) result is shown in Figure 5.

The mean (obs-calc) is $0.514 \mathrm{~K}$ for AIRS, $0.268 \mathrm{~K}$ for IASI. Inspection of Figure 5 shows an interesting effect: AIRS and IASI data track each other. The reason for this tracking is that both AIRS and IASI disagree with the ECMWF temperature and its seasonal variation by between 300 and $500 \mathrm{mK}$, a substantial amount. It can also be seen that before 
year 7.8 the IASI (obs-calc) and AIRS do not track as well. This relates to some change in the IASI on-board or ground data processing at the start of the operational data processing in July 2007, and is of the order of $100 \mathrm{mK}$.

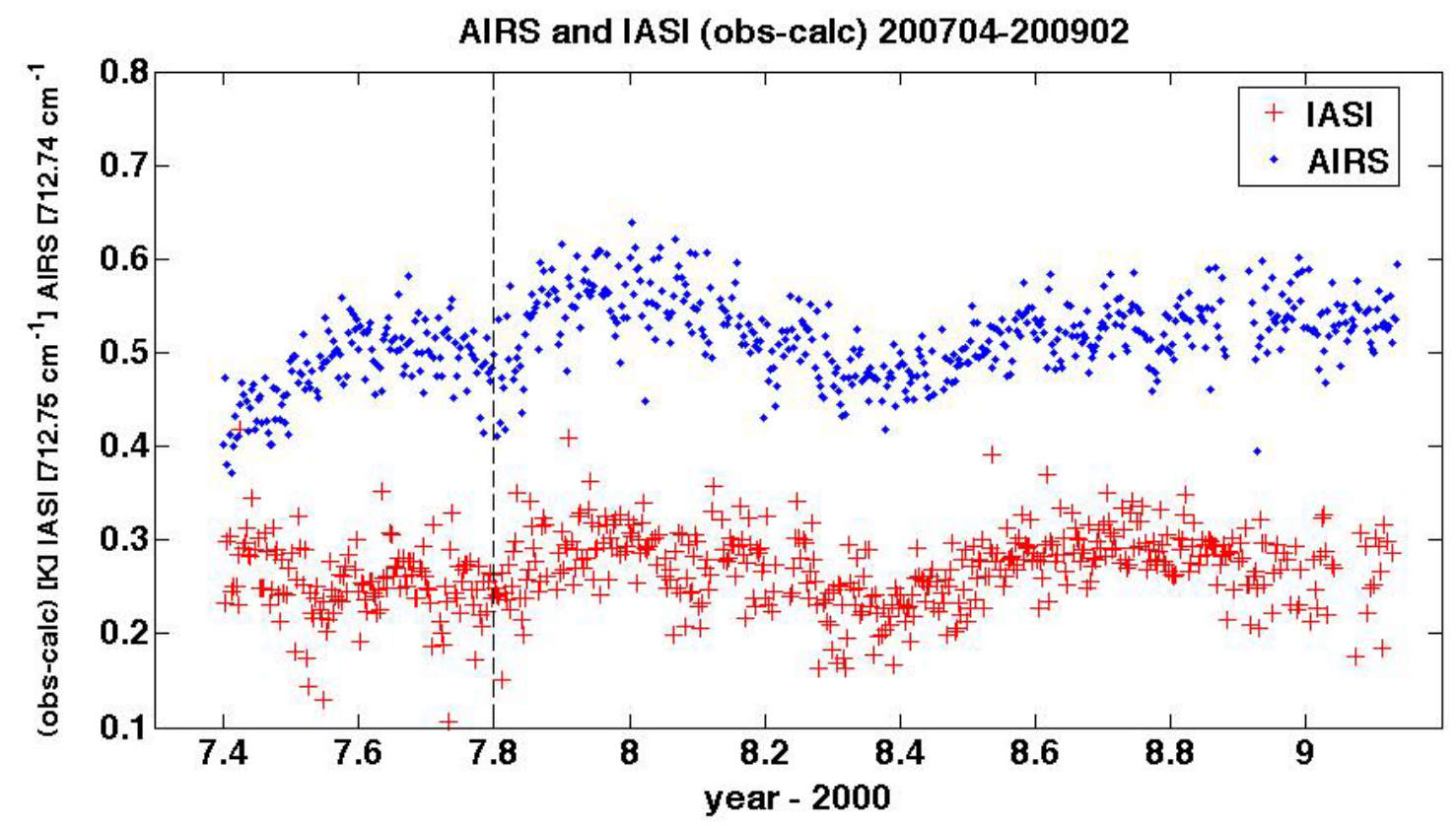

Figure 5. (obs-calc) for AIRS and IASI at $712.75 \mathrm{~cm}^{-1}$

\subsection{Lower stratospheric channel at $700.25 \mathrm{~cm}^{-1}$}

Next we look at a sounding channel at $700 \mathrm{~cm}^{-1}$ that measures the state of the atmosphere near $100 \mathrm{mb}$. Figure 6 illustrates the location of the channel using radiance calculated for a tropical profile. The figure also shows the similarity of the spectral sampling and resolution in this area of the $\mathrm{CO}_{2}$ absorption. We selected a channel at the maximum opacity between $\mathrm{CO}_{2}$ lines to minimize the effects of SRF position and shape sensitivity.

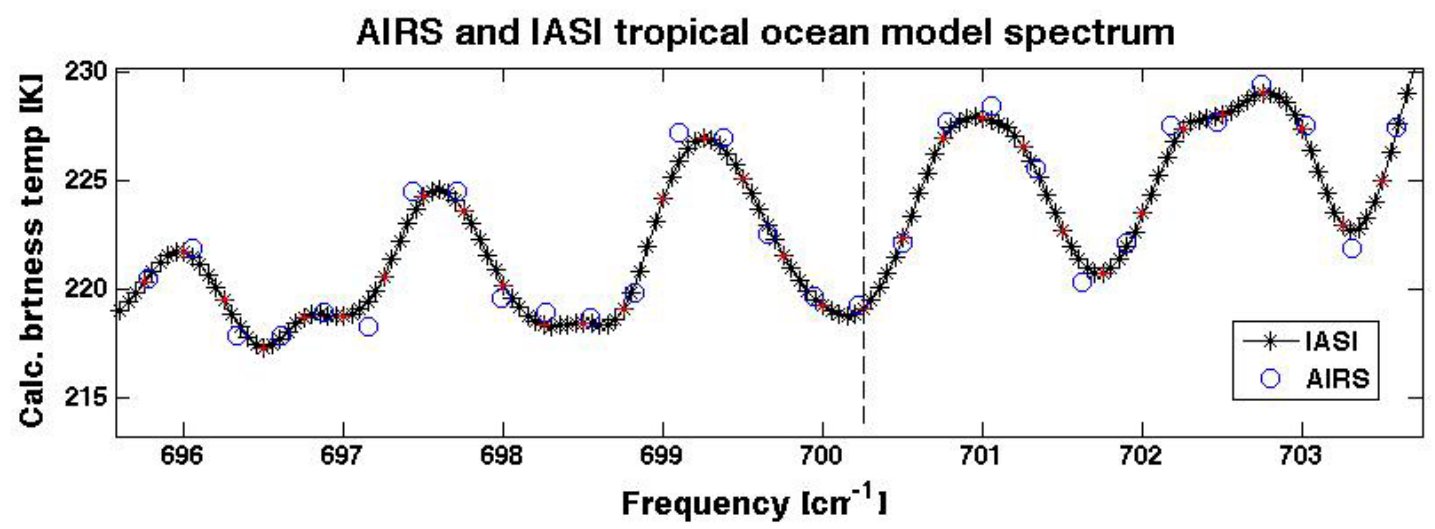

Figure 6. The calculated tropical spectrum from AIRS and IASI at $700.25 \mathrm{~cm}^{-1}$.

The channel at $700.25 \mathrm{~cm}^{-1}$ sounds the lower stratosphere near $60 \mathrm{hPa}$ at a brightness temperature of typically $219 \mathrm{~K}$. The spectral gradient at this location is $6.3 \mathrm{~K} / \mathrm{cm}^{-1}$. Figure 7 shows the results for (obs-calc). The mean of (obs-calc) for AIRS and IASI is virtually identical, $0.395 \mathrm{~K}$ and $0.404 \mathrm{~K}$. 


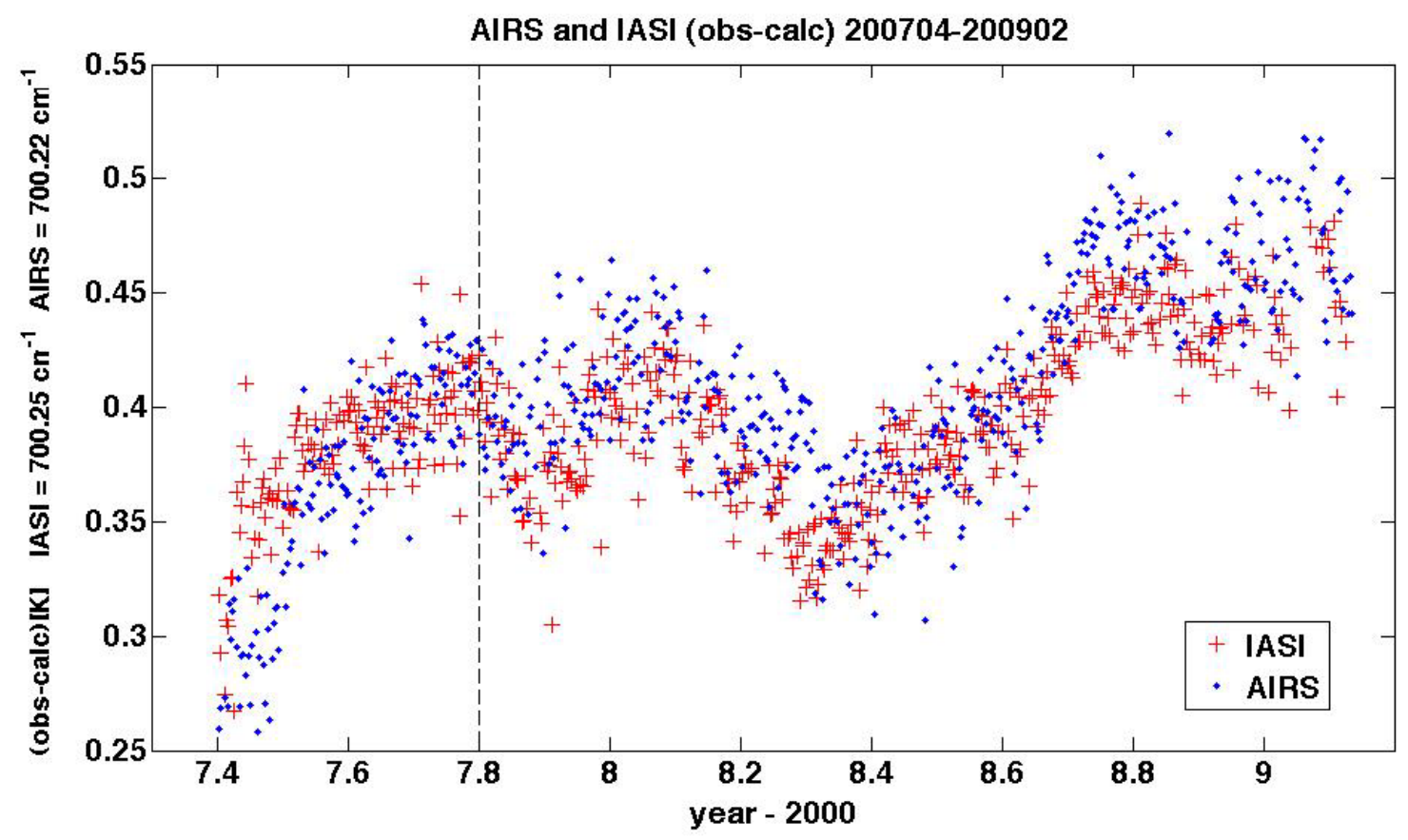

Figure 7. The overlay of two years of AIRS and IASI daily mean (obs-calc) at $700.25 \mathrm{~cm}^{-1}$ for clear night tropical ocean.

We again observe how accurately AIRS and IASI track each other, both disagreeing with an ECMWF stratospheric seasonal cycle and trend. Both instruments indicate that the temperature in the $60 \mathrm{hPa}$ region is on average $0.4 \mathrm{~K}$ warmer than in the ECMWF profiles and that the cooling in the ECMWF stratospheric temperatures is an artifact.

\section{4 (obs - calc) bias summary}

Table $1 \quad$ Summary of (obs-calc)

\begin{tabular}{|l|r|r|r|r|r|}
\hline Wave number in $\mathrm{cm}^{-1}$ & \multicolumn{1}{|c|}{2616} & 1231 & 961 & 712.75 & \multicolumn{1}{c|}{700.25} \\
\hline Average brightness temperature & $298 \mathrm{~K}$ & $296 \mathrm{~K}$ & $296 \mathrm{~K}$ & $256 \mathrm{~K}$ & $219 \mathrm{~K}$ \\
\hline AIRS (obs - calc) average & $+0.007 \mathrm{~K}$ & $-0.131 \mathrm{~K}$ & $+0.089 \mathrm{~K}$ & $+0.514 \mathrm{~K}$ & $+0.395 \mathrm{~K}$ \\
\hline IASI (obs - calc) average & $+0.053 \mathrm{~K}$ & $-0.167 \mathrm{~K}$ & $-0.013 \mathrm{~K}$ & $+0.268 \mathrm{~K}$ & $+0.404 \mathrm{~K}$ \\
\hline AIRS - IASI (obs - calc) mean double difference & $-0.046 \mathrm{~K}$ & $+0.036 \mathrm{~K}$ & $+0.102 \mathrm{~K}$ & $+0.246 \mathrm{~K}$ & $-0.009 \mathrm{~K}$ \\
\hline
\end{tabular}

\section{DISCUSSION}

1) The methodology of comparing (obs-calc) for window channels under cloud-free conditions works very well. The bias in the three window channels is $100 \mathrm{mK}$ or less. The surface temperature in the non-frozen oceans in the ECMWF model was good, and the surface model starting in September 2008 has improved them.

2) Both instruments show a colder bias at $1231 \mathrm{~cm}^{-1}(-0.131 \mathrm{~K}$ and $-0.167 \mathrm{~K})$ than at $2616 \mathrm{~cm}^{-1}$ and $961 \mathrm{~cm}^{-1}$. This may be related to an effect in the water vapor continuum model used in the radiative transfer.

3) The bias in (obs-calc) is more noisy at $1231 \mathrm{~cm}^{-1}$ and at $961 \mathrm{~cm}^{-1}$ than in $2616 \mathrm{~cm}^{-1}$ because the $1231 \mathrm{~cm}^{-1}$ and $961 \mathrm{~cm}^{-1}$ measurements require an almost factor of ten larger water vapor transmission correction, which makes the calculations that much more sensitive to the uncertainty in the water vapor from ECMWF. 
4) The fact that a seasonal pattern and a trend is seen in (obs-calc) by both instruments for both sounding channels probably relates to systematic errors in the stratospheric temperatures in the ECMWF model. Other AIRS and IASI sounding channels show similar patterns.

5) At $712.75 \mathrm{~cm}^{-1}$ there is a $246 \mathrm{mK}$ difference in (obs-calc) between IASI and AIRS. The estimated error in the rapid transmission algorithm (RTA) [Strow ${ }^{4}$ at $712.75 \mathrm{~cm}^{-1}$ is $35 \mathrm{mK}$ for AIRS, $58 \mathrm{mK}$ for IASI, independent of any SRF centroid position uncertainty. The spectral slope at the position of the $712.75 \mathrm{~cm}^{-}$ ${ }^{1}$ sounding channel is $25 \mathrm{~K} / \mathrm{cm}^{-1}$. A frequency shift of $0.01 \mathrm{~cm}^{-1}$, equivalent to $15 \mathrm{ppm}$ in the knowledge of the frequency of the SRF centroid, would be required to create a $246 \mathrm{mK}$ radiometric shift in either AIRS or IASI data. This is not consistent with the nominal $5 \mathrm{ppm}$ accuracy of the AIRS Level 1B product or the $2 \mathrm{ppm}$ accuracy of the IASI Level $1 \mathrm{C}$ product. This bias appears to be an instrumental artifact that requires further investigations. Note that at the relatively nearby $700.25 \mathrm{~cm}^{-1}$, where the spectral gradient is 6.3 $\mathrm{K} / \mathrm{cm}^{-1}$, the bias between AIRS and IASI is only $9 \mathrm{mK}$. At $700.25 \mathrm{~cm}^{-1}$ the estimated RMS error in the RTA is $13 \mathrm{mK}$ for AIRS, $15 \mathrm{mK}$ for IASI, consistent with the observed bias. A $0.01 \mathrm{~cm}^{-1}$ shift in the SRF centroid would create a $63 \mathrm{mK}$ bias shift.

6) Curiously, the change observed at $712.75 \mathrm{~cm}^{-1}$, due to some change in the IASI processing starting in July 2007, did not have an effect on the data at $700.25 \mathrm{~cm}^{-1}$ in the same band or in the three window channels. A $100 \mathrm{mK}$ effect in radiances due to a processing adjustment not related to an SI traceable quantity suggests that the calibration at this level is not SI traceable. This effect requires further investigation.

7) If we calculate the double difference we could theoretically determine the trend of IASI relative to AIRS. The analysis of the bias in (obs-calc) for the AIRS window channels for six years of data results in upper limits of $10 \mathrm{mK} /$ year relative to ECMWF. However, it is still too early to calculate any trend involving IASI. The uncertainties are too large due to the fact that we have less than two years of reliable data to work with.

Climate applications require validation of the absolute radiometric accuracy at the $30 \mathrm{mK}$ level. This is very difficult. It appears that the (obs-calc) comparison under clear conditions of two instruments, at least for the tropical oceans where ECMWF is very accurate, can demonstrate consistency at the $100 \mathrm{mK}$ level and has enough data and temporal resolution to allow for the evaluation of seasonal artifacts. However is has to be kept in mind that the excellent result with the (obscalc) presented here is restricted to spatially extremely uniform dataset, with a yield of less than $1 \%$ of the data. For climate applications all data needs to be of the highest radiometric quality. Calibration accuracy achieved under uniform clear conditions is certainly necessary, but it is not a sufficient test of the integrity of the radiometric calibration under non-uniform (cloudy) conditions in $99 \%$ of the data.

\section{CONCLUSION}

The creation of multi-decadal data sets for climate research requires better than $100 \mathrm{mK}$ absolute calibration accuracy for the full range of spectral temperatures encountered under global conditions. Evaluation of the accuracy achieved by the operational hyperspectral sounders from polar orbit is facilitated by comparing data from two instruments in orbit. The (obs-calc) double difference between AIRS and IASI using ECMWF as a transfer standard is a powerful tool which allows for validation at a better than $100 \mathrm{mK}$ level under clear conditions, and with enough temporal resolution to evaluate possible seasonal artifacts. The consistency in the seasonal patterns and the trend seen by IASI and AIRS (obscalc) show that the ECMWF model in the stratosphere contains sizeable artifacts. Calibration accuracy achieved under uniform clear conditions is certainly a necessary, but not a sufficient, test of the integrity of the radiometric calibration under non-uniform (cloudy) conditions in $99 \%$ of the data.

\section{ACKNOWLEDGEMENTS}

This work was carried out at the Jet Propulsion Laboratory, California Institute of Technology, under a contract with the National Aeronautics and Space Administration. 


\section{REFERENCES}

[1] Solomon, S., Qin, D., Manning, M., Chen, Z., Marquis, M., Averyt, K. B., Tignor, M., and Miller, H. L. (eds.), [Climate Change 2007: The Physical Science Basis. Contribution of Working Group I to the Fourth Assessment Report of the Intergovernmental Panel on Climate Change], Cambridge University Press, Cambridge, United Kingdom and New York, NY, USA, Chapter 3, (2007)

[2] Aumann, H. H., Chahine, M. T., Gautier, C., Goldberg, M. D., Kalnay, E., McMillin, L. M., Revercomb, H., Rosenkranz, P. W., Smith, W. L., Staelin, D. H., Strow, L. L., and Susskind, J. "AIRS/AMSU/HSB on the Aqua Mission: Design, Science Objectives, Data Products, and Processing Systems", IEEE Trans. Geo Sci. and Remote Sensing 41(2), 253-264 (2003)

[3] Blumstein, D., Chalon, G., Carlier, T., Buil, C., Hebert, P., Maciaszek, T., Ponce, G., Phulpin, T., Tournier, P. Simeoni, D., Astruc, P., Clauss, A., and Kaval, G., "IASI instrument: Technical overview and measured performances", Proc. SPIE 5543, 196, DOI:10.1117/12.560907 (2004)

[4] Strow, L. L., Hannon, S. E., De Souza-Machado, S., Motteler, H. E., and Tobin, D. "An Overview of the AIRS Radiative Transfer Model”, IEEE Trans. Geo Sci. and Remote Sensing 41(2), 303-313 (2003).

[5] Masuda, K., Takahima, T., and Takayama, Y. "Emissivity of pure and sea water from the model sea surface in the infrared window regions", Remote Sensing of the Environment 24, 313-329 (1988).

[6] Donlon, C.J., Minnett, P. J., Gentemann, C., Nightingale, T. J., Barton, I. J., Ward, B., and Murray, M. J., ’Toward Improved Validation of Satellite Sea Surface Skin Temperature Measurements for Climate Research", J.of Climate, 15, 353-369 (2002).

[7] Kennedy, J.J., Brohan, P., and Tett, S. F. B., "A global climatology of the diurnal variations in sea-surface temperature and implications for MSU temperature trends", GRL 34, L05712, doi:10.1029/2006GL028920, (2007).

[8] Manning, E. M., Aumann, H. H., Strow, L. L., and Hannon, S. "Spectral calibration in hyperspectral sounders", Proc. SPIE 7452, (2009) 